\title{
Prenatal Yoga Untuk Kondisi Kesehatan Ibu Hamil
}

\author{
Kadek Dwitya Widi Adnyani \\ Universitas Warmadewa \\ email : dwityawidiadnyanik@gmail.com
}

Diterima tanggal 3 Pebruari 2021, diseleksi tanggal 17 Maret 2021, dan disetujui tanggal 30 Maret 2020

\begin{abstract}
In essence, pregnancy is a natural nature that must be carried out by women which at the same time can be a threat to the safety of their souls. So that this is not a serious threat, pregnancy needs treatment with good help. One of the activities that pregnant women can do is doing prenatal yoga activities. Yoga is a form of mind body practice that originated in India. Yoga is a science that explains the link between physical, mental, and spiritual humans to achieve overall health. Prenatal yoga (yoga for pregnancy) is a modification of classical yoga which has been adapted to the physical condition of pregnant women which is done with a more gentle and slow intensity. The principles of prenatal yoga are the principles of prenatal yoga, namely breathing with full awareness. Prenatal yoga practice can help improve the health of pregnant women. Posture and breathing exercises have a relaxing effect and help reduce physical stress. There are several techniques that can be done in prenatal yoga, namely calming or centering the mind, pranayama, warming up and implementing asanas for pregnant women.
\end{abstract}

\section{Keywords: woman; pregnancy; prenatal yoga}

\section{ABSTRAK}

Kehamilan dan pada hakikatnya merupakan kodrat alam yang harus dijalankan kaum wanita yang sekaligus dapat merupakan ancaman yang terhadap keselamatan jiwanya. Agar hal tersebut tidak merupakan ancaman yang serius maka kehamilan perlu perawatan disertai pertolongan yang baik. Salah satu aktivitas yang dapat dilakukan ibu hamil adalah melaksanakan aktivitas prenatal yoga. Yoga adalah salah satu bentuk praktik pikiran tubuh yang berasal dari India. Yoga adalah sebuah ilmu yang menjelaskan kaitan antara fisik, mental, dan spiritual manusia untuk mencapai kesehatan yang menyeluruh. Prenatal yoga (yoga bagi kehamilan) merupakan modifikasi dari yoga klasik yang telah disesuaikan dengan kondisi fisik wanita hamil yang dilakukan dengan intensitas yang lebih lembut dan perlahan. Adapun prinsip dari prenatal yoga adalah rinsip prenatal yoga yaitu napas dengan penuh kesadaran. Latihan yoga prenatal dapat membantu meningkatkan kesehatan ibu hamil. Latihan postur dan pernafasan memberikan efek rileks dan membantu mengurangi stres fisik. Terdapat beberapa teknik yang dapat dilakukan pada prenatal yoga yaitu penenangan atau pemusatan pikiran, pranayama, pemanasan dan pelaksanaan asanas untuk ibu hamil.

Kata kunci : wanita; kehamilan; prenatal yoga 


\section{PENDAHULUAN}

Kehamilan didefinisikan sebagai fertilisasi atau penyatuan dari spermatozoa dan ovum serta dilanjutkan dengan nidasi atau implantasi. Kehamilan pula adalah kondisi dimana seorang wanita memiliki janin yang sedang tumbuh didalam tubuh yang pada umumnya di dalam rahim kehamilan pada manusia berkisar 40 minggu atau 9 bulan dihitung dari awal periode menstruasi terakhir sampai melahirkan. Usia kehamilan terbagi menjadi 3 trisemester dimana trisemester satu berlangsung dalam 12 minggu, trisemester kedua 15 minggu (minggu ke-13 hingga ke-27) dan trisemester tiga 13 minggu (minggu ke-28 hingga ke-40). Pada trisemester pertama, perubahan tubuh ibu belum terlalu terlihat dari luar, tapi ibu hamil sudah dapat merasakan perubahan pada dirinya seperti payudara membesar dan sakit, mood swing atau perasaan yang berubah-ubah, ngidam atau keinginan makan sesuatu yang amat sangat, morning sickness atau mual muntah terutama terjadi di pagi hari, sering buang air kencing dan konstipasi atau sulit buang air besar. Trisemester kedua, perubahan tubuh ibu semakin terlihat seperti payudara dan perut terus membesar, ibu sering kali merasa lebih bertenaga, kaki dan tangan mulai membesar atau mungkin bengkak, mulai timbul keluhan varises, dan ibu mulai merasakan gerak janin. Trisemester tiga, persalinan ibu akan semakin dekat, berat badan ibu meningkat $12-20 \mathrm{~kg}$ dan keluhan semakin banyak yang terlihat seperti perut ibu yang besar menyebabkan sesak nafas, payudara membesar dikarenakan persiapan untuk menyusui, terjadi kram otot dan kulit menjadi lebih gelap, sakit pinggang, frekuensi buang air kecil meningkat, timbul perasaan panic, khawatir, antusias dan juga gelisah (Yhossie, 2018).

Kehamilan merupakan suatu proses reproduksi yang perlu perawatan khusus agar dapat berlangsung dengan baik, karena kehamilan mengandung kehidupan ibu maupun janin (Elisabeth, 2020). Angka kematian ibu (AKI) Indonesia masih terbilang tinggi. Dimana badan kesehatan dunia World Health Organization (WHO) memperkirakan 500.000 ibu meninggal setiao tahunnya sebagai akibat langsung dari gangguan dan penyulit kehamilan (Alwan, 2013). Angka ini muncul mayoritas dari negara-negara berkembang, dimana survey penduduk antar simpus (SUPAS) dalam profil kesehatan menyebutkan bahwa AKI di Indonesia pada tahun 2015 adalah 305 per 100.000 kelahiran hidup. Berdasarkan profil kesehatan Indonesia, penyebab kematian ibu di Indonesia adalah lain-lain 40,8\%, perdarahan 30,3\%, hipertensi $27,1 \%$ dan infeksi 7,3\% (Gajjar, 2012).

Perawatan kehamilan sebagai suatu sub sistem pelayanan kesehatan sangat terkait dengan fungsi reproduksi wanita, maka upaya tersebut sangat ditentukan oleh prilaku ibu sendiri. Pengetahuan atau kognitif merupakan faktor penting dalam terbentuknya perilaku. Jika ibu hamil memiliki pengetahuan tentang gangguan dan penyulit kehamilan maka memungkinkan ibu 
mengantisipasi untuk berprilaku menjaga, mencegah dan menghindari atau mengatasi resiko terjadinya komplikasi pada kehamilan (Elisabeth, 2020). Kurangnya pengetahuan tentang bahaya kehamilan dapat menyebabkan kematian maternal, adapun hal yang dapat terjadi pada ibu yaitu perdarahan (25\%), infeksi (15\%), aborsi yang tidak aman (13\%), eklamsia (12\%), persalinan yang buruk (8\%), penyebab obsetetrik langsung lainnya (8\%) dan penyebab tidak langsung (20\%). Dimana beberapa penyebab kematian maternal tersebut disebabkan adanya komplikasi yang dapat muncul melalui tanda bahaya kehamilan (Apriliani, 2015).

Terjadi perubahan dan adaptasi psikologis dalam masa kehamilan seorang ibu pada trisemester satu, dua maupun tiga. Khususnya pada trisemester tiga ibu akan menjadi lebih protektif terhadap kehamilannya, ibu akan mulai menghindari keramaian atau seseorang yang dianggap berbahaya untuk kehamilannya. Ibu akan merasakan cemas dengan kehidupan bayi nantinya seperti apakah bayi akan lahir abnormal, apakah bayi akan dilahirkan secara normal atau apakah organ vitalnya akan mengalami cedera akibat tendangan bayi. Hal ini akan membuat ibu memilih untuk tidak melakukan aktivitas karena kecemasan yang dirasakannya (Elisabeth, 2020). Kondisi ibu yang kurang aktivitas atau kurang bergerak akan menyebabkan beberapa masalah kehamilan yang membahayakan kesehatan ibu dan janin. Akitivitas fisik menimbulan perasaan sehat pada ibu hamil, membantu relaksasi dan istirahat serta dapat meningkatkan sirkulasi yang terjadi di dalam tubuh ibu (Elisabeth, 2020).

Aktivitas fisik yang diharapkan untuk ibu hamil adalah dilakukannya latihan-latihan gerak tubuh yang dapat membantu mengurangi rasa kurang nyaman pada tubuh ibu. Rasa kurang nyaman pada fisik ibu biasanya meningkat selama trisemester kedua karena terjadinya peningkatan berat badan janin. Salah satu aktivitas latihan yang dapat dilakukan oleh ibu hamil adalah aktivitas prenatal yoga. Yoga adalah salah satu aktivitas yang dapat dilakukan ibu karena tidak hanya bermanfaat pada kebugaran fisik tapi juga mental dimana latihan yoga mengajarkan cara bernafas dalam-dalam secara sadar dan rileks. Hal inilah yang akan membantu ketika ibu hamil menghadapi persalinan (Ika,2019). Tidak hanya itu, apabila yoga dilakukan rutin terhadap ibu hamil sangat bermanfaat untuk mengatur dan meningkatkan sirkulasi darah dan mengurangi nyeri (Ika, 2019). Prenatal yoga bertujuan agar ibu hamil dapat menikmati proses kehamilan dan mempersiapkan diri untuk setiap proses persalinan, baik persalinan secara normal maupun melalui operasi caesar (Yhosie, 2018). Yoga prenatal juga merupakan salah satu bentuk yoga lembut yang dirancang untuk melengkapi kebutuhan tubuh hamil yang terus berkembang selama ketiga trimester. Latihan yoga prenatal dirancang untuk mendukung perubahan yang terjadi pada tubuh hamil. Adanya prenatal yoga membantu ibu mengenali bayi yang dikandungnya. 


\section{PEMBAHASAN}

\subsection{Kehamilan}

Kehamilan merupakan suatu proses bertemunya sperma dengan sel telur di dalam tubuh perempuan. Proses kehamilan harus ada sel spermatozoa, sel telur (ovum) yang bersatu membentuk konsepsi dan hasil konsepsi menanamkan dirinya di dalam endometrium. Melalui proses oogenesis akan terbentuk ovum dari oogonia dimana sebagaian oogonium akan mengalami perubahan-perubahan yaitu pembelahan mitosis menjadi oosit primer (46 kromosom) yang diploid kemudian menjadi oosit sekunder (23 kromosom) yang haploid (Elisabeth 2020) Spermatogonium yang dimiliki oleh laki-laki akan tumbuh dari sel primitif tubulus seminiferous testis yang relative berjumlah tetap sampai pubertas dan spermatogenesis akan dirangsang oleh hormone testosterone. Dimana pembentukan spermatozoa membutuhkan waktu 3 hari dan akan terdiri dari kepala, leher dan ekor (Ika, 2019). Pertemuan antara ovum dengan inti spermatozoa disebut dengan konsepsi atau fertilisasi yang akan membentuk zigot. Ovum yang dilepaskan dalam proses ovulasi diliputi oleh corona radiata, yang mengandung persediaan nutrisi. Setelah beberapa jam terjadi pembuaha, mulailah pembelahan zigot. Hal ini berlangsung oleh karena sitoplasma ovum mengandung zat asam amino dan enzim yang berlangsung 3 hari. Hasil konsepsi berada dalam stadium morula dan sampai di uteri hasil konsepsi atau pembuahan akan berubah menjadi blastula. Blastula akan diselingi oleh satu sampai yang terdiri dari sekelompol sel yang merupakan dinding yaitu tropoblas, dimana tropoblas akan memberikan nutrisi kepada ovum sampai terbentuk sirkulasi di dalam plasenta (Ika, 2019).

Terdapat tanda yang menandakan seorang perempuan mengalami kehamilan, salah satunya adalah amenorea. Amenorea yaitu tidak terjadinya haid pada perempuan, dimana gejala ini sangat penting karena umumnya wanita hamil tidak dapat haid lagi. Sehingga sangat penting bagi seorang perempuan mengetahui tanggal hari pertama haid terakhir, supaya dapat ditentukan umur dari kehamilan dan kapan persalinan ditentukan. Tetapi amenorea juga dapat disebabkan oleh penyakit kronik tertentu seperti tumor pituitary, perubahan dan faktor lingkungan, malnutrisi dan biasanya gangguan emosional seperti ketakutan akan kehamilan. Mual dan muntah, umumnya terjadi pada bulan-bulan pertama kehamilan, keadaan ini sering terjadi pada pagi hari tetapi tidak selalu dan keadaan ini disebut dengan morning sickness. Mual muntah biasanya dipengaruhi oleh hormon estrogen dan progesterone dimana terjadi pengeluaran asam lambung yang berlebihan sehingga menimbulkan mual dan muntah. Mammae atau payudara membesar, tegang dan sedikit nyeri disebabkan oleh pengaruh estrogen dan progesterone yang merangsang duktus dan alveoli payudara. Selain itu bersama somatomamotropin hormone tersebut akan 
menimbulkan pembesaran payudara, perasaan tegang dan nyeri selama dua bulan pertama kehamilan, pelebaran puting susu dan pengeluaran kolostrum pada ibu hamil (Ika,2019).

\subsection{Yoga}

Yoga merupakan salah satu dari enam sistem dalam filosofi india yang terdiri dari samkhaya, nyaya, vaisesika, mimasa dan Vedanta. Yoga pula merupakan sebuah ilmu yang menjelaskan kaitan antara fisik, mental dan spiritual manusia untuk mencapai kesehatan yang menyeluruh (Deva, 2017). Kata Yoga berasal dari akar kata "yuj” yang artinya menghubungkan dan yoga itu sendiri merupakan pengendalian aktivitas pikiran dan merupaka penyatuan roh pribadi dengan roh tertinggi (Gunarta, 2017). Yoga mengajarkan seseorang cara untuk mengendalikan indria-indria dan gelojak pikiran ke arah yang positif, cara mengembangkan konsentrasi dan meditasi mendekatkan diri kepada tuhan. Dalam konteks aslinya yoga adalah praktik pengembangan spiritual untuk melatih tubuh dan pikiran.

Berlatih yoga secara teratur dapat memberikan manfaat kesehatan fisik dan mental dimana yoga memang berfokus pada kecenderungan alami tubuh dalam menjaga kesehatan dan melakukan penyembuhan diri. Tujuan yoga pula adalah unuk menyiapkan dan menciptakan kekuatan, kesadaran dan harmoni baik dalam pikiran dan tubuh. Manfaat fisik yang didapatkan oleh seseorang melalui aktifitas yoga adalah meningkatkan fleksibilitas, meningkatkan kekuatan dan tonus otot, meningkatkan respirasi, energy serta vitalitas, mempertahankan metabolism seimbang, menurunkan berat badan, jantung dan kesehatan sirkulasi, peningkatan kinerja atletik dan perlindungan dari cedera. Selain manfaat fisik, salah satu manfaat terbaik yoga adalah bagaimana latihan ini dapat membantu seseorang dalam mengelola stress yang dirasakan. Stress dapat menampakkan diri sebagai sakit punggung atau leher, gangguan tidur, sakit kepala, penyalahgunaan obat-obatan dan ketidak mampuan dalam berkonsentrasi. Hal ini sering dialami oleh ibu hamil, sehingga latihan yoga khususnya sangat disarankan untuk ibu hamil karena memiliki banyak manfaat dan membantu ibu hamil mempersiapkan persalinan (Ika, 2019).

\subsection{Prenatal Yoga}

Prenatal yoga atau yang biasa dikenal dengan yoga untuk kehamilan merupakan modifikasi dari yoga klasik yang telah disesuaikan dengan kondisi fisik wanita hamil sehingga dilakukan dengan intensitas yang lebih lembut dan perlahan. Terdapat berbagai keuntungan yang akan didapatkan ibu hamil apabila melakukan prenatal yoga yang sesuai dengan masa kehamilannya seperti relaksasi dan mengatasi stress, menjaga stamina dan kesehatan, meningkatkan sirkulasi darah, membantu mengatasi rasa nyeri, mempersiapkan fisik dan mental 
untuk proses persalinan, mempercepat proses penyembuhan setelah melahirkan dan membantu ibu dalam menikmati masa kehamilan (Yhosie, 2018). Tidak hanya itu, prenatal yoga yang dilakukan khususnya pada masa kehamilan trisemester ketiga juga merupakan salah satu solusi yang bermanfaat sebagai media self help yang akan mengurangi ketidaknyamanan selama hamil, membantu proses persalinan, dan bahkan mempersiapkan mental untuk masa-masa awal setelah melahirkan dan saat membesarkan anak, selain meningkatkan kondisi fisik ibu namun juga berperan dalam mendukung proses penerimaan perubahan kondisi fisik oleh ibu selama hamil. (Apriliani, 2015).

Terdapat tiga aturan utama dalam prenatal yoga yaitu tidak menekan area sekitar perut, tidak meregangkan area sekitar perut dan tidak memutar area disekitar perut. Selain itu dalam prenatal yoga tidak dianjurkan untuk melakukan peregangan yang berlebihan hal ini karena tubuh wanita yang sedang hamil akan memproduksi hormone relaxin yang bertujuan membuat sendi-sendi lebih longgar sebagai persiapan proses jalan lahir bayi sehingga berefek pada tubuh wanita hamil menjadi lebih lentur maka dari itu tidak dianjurkan untuk melakukan peregangan yang berlebihan pada ibu hamil agar tidak mengakibatkan terjadinya cedera. Tidak melakukan inversi secara berlebihan, dimana saat hamil jumlah darah dan air di dalam tubuh meningkat sehingga memberi beban yang lebih pada jantung, apabila ibu hamil melakukan gerakan inversi maka akan meningkatkan beban jauh lebih banyak lagi pada jantung dan sering menimbulkan keluhan sesak napas. Ibu hamil tidak diperkenankan melakukan gerakan posisi terlentang. Hal ini dikarenakan di dekat tulang belakang terdapat vena cava inferior yang membawa darah dari tubuh bagian bawah kembali ke jantung, apabila ibu hamil mengambil posisi terlentang akan menekan vena cava inferior dan menyebabkan peredaran darah terganggu sehingga menimbulkan keluhan tekanan darah. Selain itu hal yang harus diperhatikan apabila ibu hamil melakukan prenatal yoga adalah perpindahan posisi. Perpindahan posisi secara tiba-tiba sering menimbulkan rasa pusing pada ibu hamil, terutama dari posisi duduk ke posisi berdiri sehingga dianjurkan agar ibu hamil tidak mengambil perubahan posisi secara mendadak (Yhosie, 2018).

Persiapan yang harus dilakukan ibu apabila melakukan prenatal yoga adalah menggunakan alat bantu yoga yang biasa disebut dengan props. Props bisa berupa matras, balok kayu, balok busa, guling, belt, kursi, selimut dan tembok. Selain itu ibu hamil harus mengenenakan pakaian yang pas (tidak terlalu longgar dan tidak terlalu ketat), berbahan ringan dan menyerap keringat. Berlatih tanpa alas kaki (kaos kaki atau sepatu) diatas matras yoga yang anti slip untuk mencegah resiko terpeleset dan terkilir. Ibu hamil dianjurkan berlatih dalam ruangan yang sama dan dengan waktu yang sama setiap harinya untuk menciptakan suasana dan memudahkan pikiran ibu langsung menyatu dengan suasana yoga. Ibu dapat pula menyetel 
musik yang lembut saat berlatih untuk menciptakan suasana pikiran yang tenang. Hal terpenting yang perlu disiapkan oleh ibu hamil saat melakukan prenatal yoga adalah mengosongkan perut sebelum berlatih, 2 jam setelah makan berat dan 1 jam setelah makan ringan. Minum air sesering mungkin sebelum, setelah, dan saat berlatih. Ibu hamil sangat mudah terkena dehidrasi yang dapat membahayakan ibu dan janin.

\subsection{Tahapan Prenatal Yoga Untuk Ibu Hamil}

Pada prenatal yoga hal yang paling penting untuk ibu hamil adalah tujuan yang akan dirasakan oleh ibu hamil dan janinnya. Awal mula latihan dimulai latihan prenatal yoga pada ibu hamil, haruslah dilakukan pemusatan pikiran (Yhosie, 2018). Hal ini bertujuan agar pikiran ibu saat melakukan latihan yoga tidak tertinggal pada pekerjaannya, keperluan suami dan keluarga dan sebagaiannya. Seorang instruktur atau ibu yang berlatih mandiri harus mampu menenangkan pikiran dan memusatkan perhatian serta melakukan focus saat latihan hanya antara dirinya dan janin yang ada di dalam perut. Ibu hamil dapat menggunakan kata-kata positif untuk membangkitkan kembali rasa tenang, semangat, percaya diri dan nyaman untuk menyugesti diri agar mendapatkan ketenangan. Setelah menenangkan diri dan pikiran, ibu diharapkan melanjutkan dengan pranayama. Pranayama atau latihan pernapasan perlu dilatih karena napas adalah salah satu unsur penting dalam keberhasilan mengejan saat persalinan normal (Yhosie, 2018). Ibu hamil pula sering mengalami sesak nafas dan nafas yang pendek diakibatkan membesarnya tubuh dan desakan janin yang ada diperut, sehingga apabila ibu melakukan pranayama secara rutin akan membantu masuknya oksigen ke dalam tubuh yang membuat ibu semakin bugar dan sehat. Pranayama pula meningkatkan efisiensi kadar oksigen yang masuk ke dalam darah, otot, dan jantung. Dampaknya, napas jadi lebih panjang dan pembuluh darah melebar untuk mengakomodasi aliran darah yang semakin banyak dan lancar. Pada akhirnya, jantung jadi lebih kuat dan denyutnya meningkat. Kerja jantung yang lebih baik ini akan membantu memompa darah ke seluruh tubuh dan menstabilkan irama jantung.
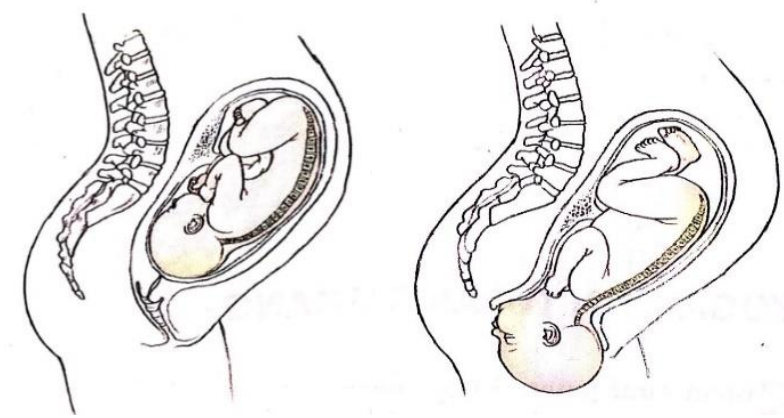

Gambar 1. Kehamilan

(Leslie, 2010) 
Setelah melakukan penenangan dan pranayama, ibu dapat melakukan pemanasan atau warming up. Hal ini dilakukan agar tubuh ibu tidak merasa kaget sebelum melakukan latihan yoga. Ibu hamil diharapkan agar melakukan pemanasan dengan gerakan yang lembut dan perlahan. Gerakan yang lembut dan mengalir akan membuat tubuh ibu lebih luwes sekaligus kuat. Gerakan lembut tersebut dapat berubah meluruskan kedua lengan, kaki, memutar leher secara perhalan dan menggerakkan jari-jari kaki. Pemanasan yang tepat pada ibu juga digunakan untuk memperhatikan kemampuan dan kesanggupan kondisi ibu yang akan melakukan aktivitas latihan prenatal yoga dan menentukan bentuk latihan berikutnya. Ketika kondisi tubuh ibu sudah merasa siap untuk melaksanakan prenatal yoga, ibu dapat melanjutkan aktivitas prenatal yoga asanas. Prenatal yoga asanas akan membantu ibu dalam mempersiapkan kelahiran dan meyakinkan diri atas kehamilan yang sedang dijalaninya. Prenatal yoga bisa dilakukan oleh ibu hamil sekitar 1-2 kali semingu selama 60-75 menit. Adapun beberapa kelompok prenatal yoga asanas yang dapat dilakukan oleh ibu hamil adalah:

\section{Vrksasana}

Vrksasana berasal dari kata vrksa yang berarti pohon, selain itu asanas ini merupakan salah satu pose keseimbangan berdiri asimetris tingkat dasar (Leslie, 2010). Langkah melakukan vrksasana adalah berdiri dengan pose tadasana, kemudian pindahkan berat badan ke kaki kanan, tekuk lutut kiri dan letakkan telapak kaki kiri di punggung kaki kanan, betis kanan atau di paham dalam kemudian satukan kedua tangan di depan dada, tahan beberapa saat, jaga keseimbangan dan kestabilan tubuh, kemudian lakukan pada kaki yang sebaliknya.

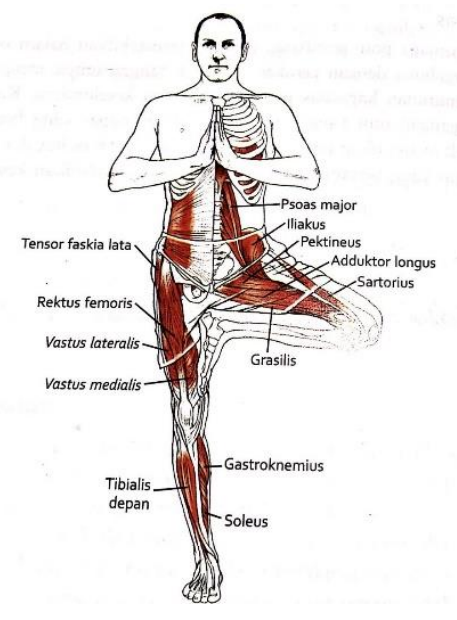

Gambar 2. Vrksasana

(Leslie, 2010)

Pose ini harus diseimbangkan dengan pernapasan yang teratur, apabila ibu hamil dapat melakukan pose ini dengan pernapasan yang teratur akan mendapatkan hasil yang maksimal. Ibu akan merasakan ketenangan dan keseimbangan yang nyaman dari pose ini. Latihan 
keseimbangan pada pose ini membantu ibu bernapas dengan baik sehingga janin yang ada di dalam kandungannya mendapatkan asupan oksigen yang baik (Yhosie, 2018).

\section{Virabhadrasana I}

Virabhadra berarti nama ksatria hebat dalam mitor, pose ini disebut pula sebagai warrior I (Leslie, 2010). Apabila akan melakukan pose ini ada beberapa langkah yang harus dilakukan oleh ibu hamil yaitu berdiri dengan posisi tadasana, kemudian mundurkan kaki kiri ke belakang, lalu tekuk lutut kanan ke arah jari kaki, lutut tidak boleh melebihi tumit, jika ibu hamil mampu dan merasa nyaman letakkan telapak kaki kiri di lantai kemudian letakkan tangan di pinggang atau bawa kedua tangan ke atas sejajar dengan telinga kemudian tahan beberapa saat dan lakukan pada sisi yang sebaliknya.

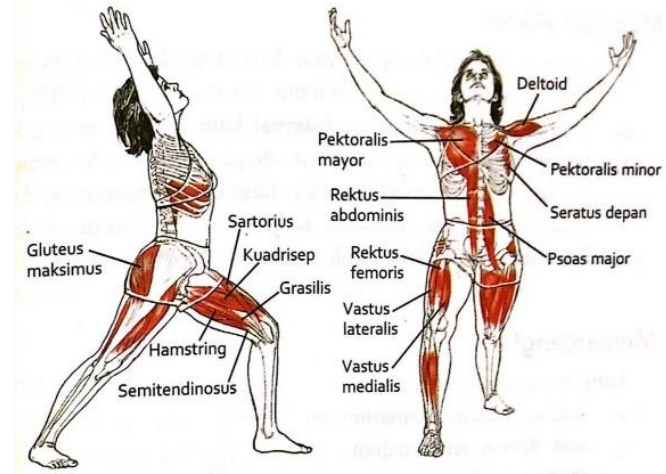

Gambar 3. Virabhadrasana I

(Leslie, 2010)

Pose ini baik untuk kondisi ibu hamil, gerakan ini melatih otot-otot disekitar punggung dada dan pinggul. Beberapa otot disekitar area perut ibu hamil juga teregangkan seperti musculus rectus abdominis, musculus seratur anterior, musculus pectoralis minor dan musculus psoas mayor. Pose ini pula harus di kombinasikan dengan pola pernapasan yang teratur. Dalam semua pose warrior I harus memposisikan dan menjaga relasi panggul dengan kaki dan tubuh. Apabila tubuh ibu bagian bawah tidak bisa efektif menyangga (Sthira) tubuh bagian atas, maka pernapasan tidak akan cukup mudah (sukha) dilakukan (Leslie, 2010). Warrior I baik dilakukan untuk ibu hamil yang terlalu sering duduk dengan waktu yang lama karena dapat memperbaiki otot-otot sakroiliaka yang mengalami gangguan seperti nyeri. Selain itu gerakan ini ermanfaat untuk meningkatkan stamina dan daya tahan tubuh, menguatkan otot jantung, melancarkan pencernaan, menguatkan otot-otot tubuh pada kaki seperti hamstring, semitendinosus dan sartorius, paha, dasar panggul, bahu dan punggung pada ibu hamil (Yhosie,2018). 


\section{Bitilasana Marjariasana}

Gerakan ini memberikan efek yang sangat baik kepada ibu hamil apabila dilakukan dengan benar. Bitilasana majariasana disebut pula sebagai pose cow pose-cat pose, dimana pada pose ini ibu hamil menarik badan ke dalam dan keluar dengan diimbangi pernapasan. Adapun langkah untuk melakukan pose ini adalah mempersiapkan diri dengan posisi menyerupai meja, lalu menarik napas dan mengangkat sedikit kepala ke arah depan, jauhkan bahu dan telinga, tulang ekor diarahkan sedikit ke atas membentuk cow pose. Lalu hembuskan napas, tundukkan kepala ke bawah, bawa masuk tulang ekor ke arah dalam membentuk cat pose kemudian ulangi gerakan tersebut beberapa kali.

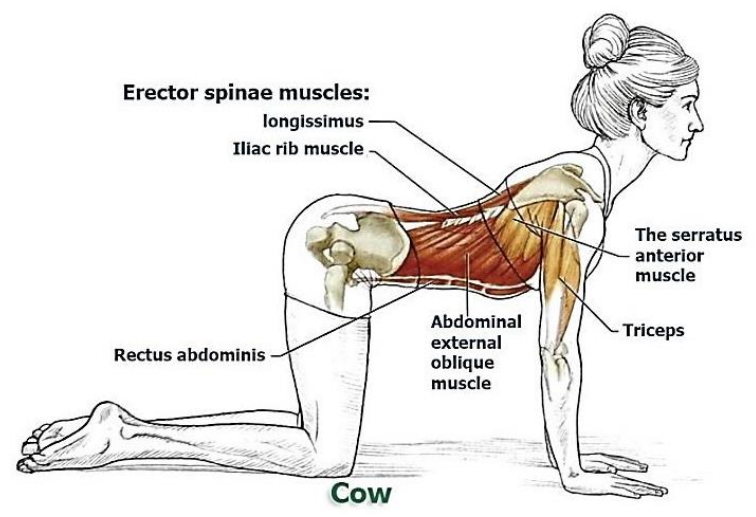

Gambar 4. Bitilasana Marjariasana (imgur.com)

Kemungkinan kesalahan pada gerakan ini adalah sering terjadinya badan kolaps, perut menggantung dan posisi panggul yang anterior tilt. Kesalahan tersebut akan menyebabkan beban berpindah ke bagian pinggang ibu, sehingga ibu hamil akan merasakan nyeri atau sakit (Yhosie,2018). Untuk mencegah hal tersebut ibu sebaiknya berusaha membawa kembali panggul ke posisi netral untuk menghindari adanya beban di pinggang. Pose cow pose-cat pose mengembangkan fleksibilitas di tulang belakang dan merupakan salah satu latihan yang sering direkomendasikan untuk nyeri punggung. Ibu hamil yang sering mengalami nyeri dibagian punggung sangat direkomendasikan untuk melakukan gerakan ini mengingat manfaat yang dapat dirasakan apabila melakukan gerakan ini. Selain mengurangi nyeri di punggung gerakan ini mengencangkan dan meregangkan otot perut yaitu musculus rectus abdominis dan musculus obliqus external

\section{Parivrtta Janu Sirsasana}

Parivrtta Janu Sirsasana berasal dari kata parivrtta yang berarti berputar, janu yang berarti lutut dan shiras yang berarti menyentuh dengan kepala (Leslie, 2010). Pose ini biasa dikenal dengan sebutan revolved head to knee pose. Adapun langkah dalam melakukan pose 
ini adalah ambil posisi duduk terlebih dahulu kemudian luruskan kedua kaki. Tekuk dan buka lutut kanan ke arah lantai, dekatkan tumit kanan ke paha dalam kiri, letakkan tangan kiri di lantai, tarik nafas kemudian angkat tangan kanan ke atas, hembuskan nafas dan bawa tangan kanan ke arah kiri lalu rasakan peregangan pada sisi kanan tubuh. Untuk menyeimbangkan, gerakan ini harus dilakukan pada arah yang berlawanan sehingga tidak hanya pada satu sisi tubuh saja yang merasakan peregangan namun juga pada kedua sisi. Kondisi ibu hamil tidak diharapkan memaksakan tubuh pada gerakan ini, ibu dianjurkan untuk melakukan gerakan sesuai dengan kemampuan tubuhnya.

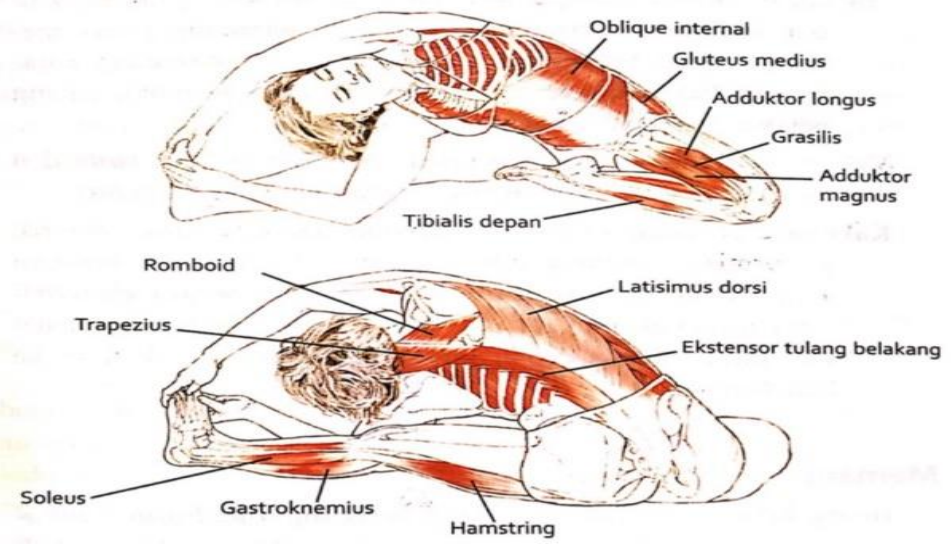

Gambar 5. Parivrtta Janu Sirsasana

(Leslie, 2010)

Otot-otot yang berada di tulang belakang akan teregangkan sehingga memberikan sensasi yang menenangkan untuk ibu, adapun otot-otot tersebut adalah musculus obliqus internal, musculus trapezius, musculus rhomboideus, musculus latissimus dorsi dan musculus extensor. Pose ini pula dapat meningkatkan pencernaan dan meredakan sakit kepala dan insomnia. Untuk mendapatkan hasil yang diharapkan pada pose ini ibu hamil harus menghindari kesalahankesalahan yaitu tidak memutar leher berlebihan atau memaksakan, tidak memaksakan tubuh untuk sejajar hal ini dikarenakan wanita hamil memiliki perut yang lebih besar sehingga diharapkan ibu hamil tidak memaksakan kondisi tubuhnya namun tetap melakukan gerakan semaksimal mungkin.

\section{Supta Baddha Konasana}

Supta Badhha Konasanasa ini dapat meningkatkan sirkulasi darah di perut bagian bawah, meregangkan organ vital ibu hamil, dan meningkatkan rotasi eksternal di pinggul dan sangat bagus untuk menenangkan pikiran. Berasal dari kata supta yang berarti istirahat dan merebahkan tubuh untuk tidur, Baddha yang berarti terikat dan kona yang berarti sudut (Leslie,2010). Gerakan ini merupakan variasi dari baddha konasana yang dapat menyebabkan 
tulang belakang berada dalam satu garis yang netral atau ekstensi yang sangat ringan untuk bernapas. Adapun langkah yang harus dilakukan ibu hamil untuk melakukan gerakan ini adalah menyusun alat bantu seperti guling membentuk tanda tambah (+), lalu duduk di depan guling dan menyatukan kedua telapak kaki, apabila diperlukan dapat menggunakan belt. Perlahan sandarkan punggung pada guling, letakkan kedua tangan disamping kanan kiri tubuh, telapak tangan menghadap atas. Gunakan bantal untuk membuat posisi lengan lebih nyaman dan usahakan agar tubuh relaks sambil memejamkan mata dan nikmati semua sensasi yang terjadi di dalam tubuh.

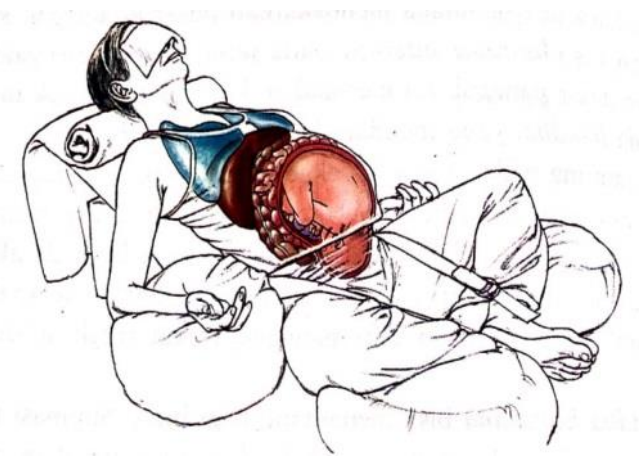

Gambar 6. Supta Baddha Konasana (Leslie, 2010)

Pose ini membantu ibu dalam mempersiapkan kelahiran, dimana pose ini membuat otot panggul dan paha lebih kuat untuk melawan tekanan persalinan (Yhosie,2018) Pose Supta Baddha Konasana merupakan pose yoga restoratif menghilangkan stres dalam tubuh dengan merelaksasikan organ dalam. Efek yang lebih besar dari Supta Baddha Konasana dapat dialami jika punggung bawah ditopang dan diangkat dengan guling dan selimut serta pernapasan terkendali.

Gerakan yang telah disebutkan diatas merupakan gerakan yang sangat dianjurkan untuk dilakukan oleh ibu hamil. Prenatal yoga di rancang khusus untuk ibu hamil dalam mempersiapkan kehamilan dan proses kelahiran sang bayi. Pemusatan pikiran, pranayama, pemanasan, kemudian dilanjutkan dengan asanas merupakan kombinasi yang tepat, dimana ibu dapat terbantu dalam menjaga kondisi kesehatan tubuhnya saat mengalami proses kehamilan. Asanas-asanas yang telah disebutkan di atas juga dapat di kombinasikan dengan gerakan atau pose lainnya yang dapat pula mendukung kondisi kesehatan ibu. Lima asanas yang telah disebutkan diatas terbagi menjadi stabilisasi, peregangan sisi samping tubuh, persiapan proses kelahiran dan restorative.

Stabilisasi pada ibu hamil sangat dibutuhkan karena perubahan beban di dalam tubuh akan membuat perubahan dalam kestabilan badan. Pusat gravitasi di dalam tubuh pun ikut 
mengalami perubahan yang diakibatkan adanya beberapa hormon yang ikut berperan saat terjadi kehamilan salah satunya adalah hormon relaxin yang menyebabkan sendi-sendi lebih longgar. Fungsi pose stabilisasi dapat membantu menstabilkan postur tubuh dalam membawa beban. Peregangan sisi samping tubuh berguna untuk relaksasi pada beberapa otot ibu hamil khususnya musculus quadratus lumborum, musculus erector spina, musculus oblique externa, musculus obliqus interna. Selain itu pula menjaga kelenturan sendi-sendi tulang belakang, memberi ruang pada rongga dada untuk mengembang pada saat bernapas sehingga memberikan kesempatan bagi paru-paru untuk mengembang dengan optimal (Yhosie, 2018). Kunci utama dari peregangan sisi samping tubuh adalah tidak melakukan pemaksaan terlalu dalam dan menahan suatu pose dalam posisi yang nyaman. Beberapa gerakan pula dibutuhkan untuk mempersiapkan proses persalinan pada ibu hamil. Pada proses persalinan, area panggul dan sekitarnya menjadi daerah yang paling di fokuskan. Semua proses persalinan memerlukan kelenturan sendi panggul untuk dapat terbuka lebar atau abduksi sendi panggul. Adapun manfaat pada pose persiapan proses persalinan adalah untuk melenturkan area-area otot panggul dan paha antara lain musculus hamstring, musculus adductor, musculus quadriceps femoris dan musculus gluteus. Selain itu dengan mengenal gerakan-gerakan ini sebelum melahirkan, ibu hamil akan terbiasa dengan posisi persalinan dan otot-otot akan semakin rileks (Yhosie,2018).

Waktu paling tepat untuk memulai yoga ibu hamil adalah pada kehamilan trimester kedua atau 14 minggu ke atas. Meski ada beberapa gerakan yoga yang lembut dan aman dilakukan di trimester pertama kehamilan, ibu hamil terutama yang belum pernah mencoba yoga sebelumnya disarankan melakukan prenatal yoga sampai trimester kedua. Pada trisemester pertama dapat dilakukan persiapan-persiapan kecil sebelum memulai prenatal yoga, ada baiknya ibu hamil ditemani oleh instruktur agar mendapatkan latihan yang maksimal dan terarah. Prenatal yoga pada trisemester kedua sangat dibutuhkan karena sendi-sendi ibu hamil mulai longgar sehingga ibu akan merasakan dampak yang besar apabila rutin melakukan prenatal yoga (Ika, 2019). Sedangkan pada trisemester ketiga timbul perasaan-perasaan kurang mengenakan pada ibu seperti cemas dan rasa takut sehingga dengan melakukan prenatal yoga ibu akan dibiasakan untuk tetap tenang dan meyakini dirinya sendiri untuk mampu melewati proses kehamilan.

\section{PENUTUP}

Latihan prenatal yoga pada ibu dapat membantu meningkatkan kesehatan ibu hamil. Latihan postur dan pernafasan memberikan efek rileks dan membantu mengurangi stres fisik. 
Sementara itu, bertambahanya informasi serta terasahnya keterampilan ibu hamil dalam mengendalikan kondisi tubuhnya, membantu menambah keyakinan dan kemampuan diri ibu hamil dalam menghadapi masa menjelan persalinanPrenatal yoga dapat dilakukan melalui gerakan tubuh yang disertai teknik pegaturan nafas dan pemusatan konsentrasi, fisik akan lebih sehat, bugar, kuat, emosi akan lebih seimbang. Prenatal yoga dapat mengurangi rasa sakit, cemas, rasa takut, menguatkan otot, tidur lebih nyaman dan mempermudah proses persalianan.

\section{DAFTAR PUSTAKA}

Alwan, M., Zakaria, A. A., Rahim, M. A., Hamid, N. A., \& Fuad, M. F. (2013). Comparison between Twi Relaxation Methods on Competitive State Anxiety Among Colege Soccer Teams During Pre-Competitions Stage. International Journal of Advanced Sport Sciences Reasearch, 1, 90-104.

Apriliani, R. A., \& Wahyudi, H. (2015). Pengaruh Yoga Prenatal terhadap Kecemasan Sesaat dalam Menghadapi Persalinan pada Primigravida Trimester III di Galenia Mom and Baby Center Kota Bandung. Prosiding Psikologi, 287-293.

Deva, Govind Sastry \& Ballantyne J.R. 2017. Yoga Sutra Patanjali. Surabaya : Paramita

Elisabeth. 2020. Perawatan Kehamilan dan Menyusui Anak Pertama. Pustaka Baru Press. Yogyakarta.

Gajjar, N. (2012). Effect of Yoga Exercises on Achievement. International Journal for Research in Education (IJRE), 1(1).

Gunarta Ketut. 2017. “Implementasi Pembelajaran Yoga Dalam Meningkatkan Konsentrasi Belajar Di Sekolah Dasar Negeri 1 Sumerta”. Institut Hindu Dharma Negeri Denpasar. Vol 3 No 2

Leslie Kaminoff. 2010. The Wonder Of Yoga. New York City

Ika. 2019. Kebidanan Komplementer Terapi Komplementer dalam Kebidanan. Pustaka Baru Press. Yogyakarta

Yhosie, 2018.Prenatal Postnatl Yoga. Penerbit Buku Kompas. Jakarta 